Article

\title{
The Effect of the Gaseous Environment on the Electrical Conductivity of Multi-Walled Carbon Nanotube Films over a Wide Temperature Range
}

\author{
Dawid Janas ${ }^{1, *(\mathbb{D})}$ and Krzysztof K. Koziol ${ }^{2,3}$ \\ 1 Department of Chemistry, Silesian University of Technology, B. Krzywoustego 4, 44-100 Gliwice, Poland \\ 2 Department of Materials Science and Metallurgy, University of Cambridge, 27 Charles Babbage Rd, \\ Cambridge CB3 0FS, UK; kk292@cam.ac.uk \\ 3 Department of Transport and Manufacturing, Cranfield University, College Road, Cranfield MK43 0AL, UK \\ * Correspondence: Dawid.Janas@polsl.pl; Tel.: +48-32-237-10-82
}

Received: 7 November 2019; Accepted: 20 January 2020; Published: 21 January 2020

\begin{abstract}
The surrounding gas atmosphere can have a significant influence on the electrical properties of multi-walled carbon nanotube (CNT) ensembles. In this study, we subjected CNT films to various gaseous environments or vacuum to observe how such factors alter the electrical resistance of networks at high temperatures. We showed that the removal of adsorbed water and other contaminants from the surface under reduced pressure significantly affects the electrical conductivity of the material. We also demonstrated that exposing the CNT films to the hydrogen atmosphere (as compared to a selection of gases of inert and oxidizing character) at elevated temperatures results in a notable reduction of electrical resistance. We believe that the observed sensitivity of the electrical properties of the CNT films to hydrogen or vacuum at elevated temperatures could be of practical importance.
\end{abstract}

Keywords: carbon nanotubes; thin films; electrical conductivity

\section{Introduction}

The discovery of carbon nanotubes (CNTs) in 1991 [1] brought a new player into the field of engineering able to surpass many technological limitations of classical materials. Due to their unique nanostructure, which translates into impressive electronic [2,3], thermal [4], and mechanical [5] properties, an unprecedented level of performance has been observed for individual CNTs. As a consequence, they have become one of the most promising candidates for many applications ranging from nanoactuators [6], nanobatteries [7], nanosensors [8] to other forms of nanodevices [9-11]. Breakthrough in the production of CNT ensembles beyond the laboratory scale from the liquid [12] or solid medium $[13,14]$ and further research advances have eventually led to the creation of real-life scale CNT applications such as heaters [15], cloaking systems [16] or hologram emitters [17].

Interestingly, these 1D conductors have revealed that their electronic character is quite sensitive. The exposure of CNT ensembles to a number of chemical species has been found to have a strong influence on their electrical properties [18]. Because of this, and the fact that their surface area reaches up to $1000 \mathrm{~m}^{2} \cdot \mathrm{g}^{-1}$ [19], there is a particular interest in the application of CNTs in the field of gas sensing. There have been numerous reports on using CNTs as sensors of hydrogen [20], oxygen [21], methane [22], and many more [23-26], a prevailing number of which, however, operate at room temperature. Since a wide spectrum of processes in the industry actually takes place at elevated temperatures, it is of high importance to develop sensors able to work under non-standard conditions.

In this work, we used the direct-spinning method to produce multi-walled CNT films in a single step [13], which were then engaged as resistive heating elements as previously reported [15]. This 
time, however, they were exposed to various gaseous environments while kept at high temperatures. The motivation was to probe what is the influence of particular gaseous species on the electrical properties of CNT films under non-ambient conditions. For this purpose, we chose high-vacuum, as well as a selection of inert, oxidizing, and reducing environments. The results showed that interaction with the surrounding gas makes an impact on the mobility of charge carriers within the explored temperature range. Firstly, we quantified the influence of the vacuum level on the electrical resistance of CNT ensembles at $100^{\circ} \mathrm{C}$. Then, we gauged the change in electrical resistance when the CNT films were exposed to different gaseous environments within room temperature at a $-300{ }^{\circ} \mathrm{C}$ temperature window. Finally, we observed how the elimination of oxidizing species allows for strong and stable incandescence from these resistively heated CNT films.

\section{Materials and Methods}

\subsection{Synthesis of CNT Films}

Methane was subjected to chemical vapor deposition (CVD) catalyzed by ferrocene (p.a.; Sigma-Aldrich, Gillingham, UK) and promoted by thiophene (p.a.; Sigma-Aldrich, Gillingham, UK) inside of a vertical reactor kept at $1200{ }^{\circ} \mathrm{C}$ under hydrogen. Continuously produced aerogel that formed inside was drawn directly out from the reactor and transferred onto a fast-spinning winder to yield $10 \mu \mathrm{m}$ thick CNT films made up of multi-walled CNTs as previously described (Figure 1) [13,27].

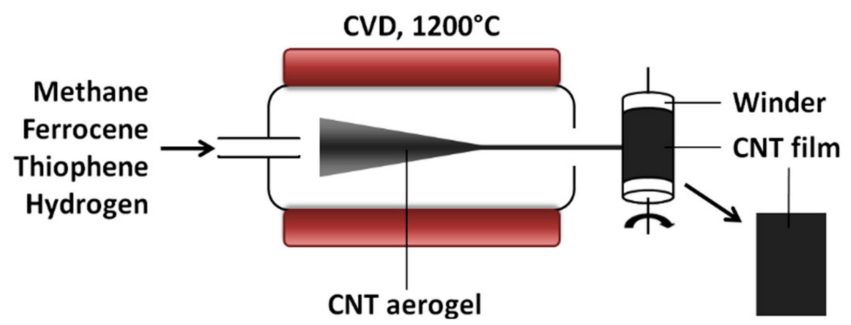

Figure 1. Experimental setup for the synthesis of carbon nanotube (CNT) films by the direct-spinning method.

The material was then cut with a razor blade into $10 \mathrm{~mm} \times 40 \mathrm{~mm}$ specimens, peeled off the substrate, and transferred onto custom-designed sample holders (Figure 2). The U-shaped holders were made of glass and equipped with Al tape electrical terminals between which the CNT films were placed. Ag conductive paint was used to minimize the possible effect of contact resistance between nanocarbon and the Al terminals through which current was delivered.

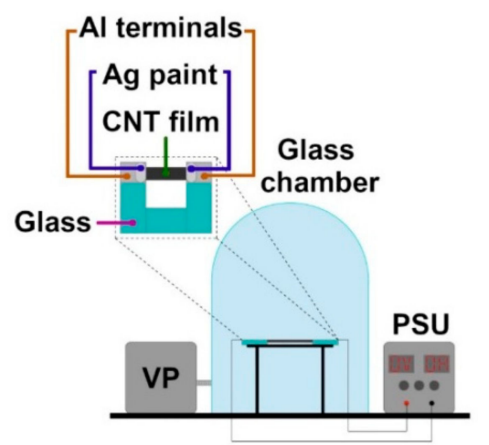

Figure 2. Experimental setup for testing of CNT films (sample holder magnified). VP-vacuum pump; PSU- power supply unit. 


\subsection{Assessing the Electrothermal Properties}

Previously reported methodology [15] was adopted to find the dependence between employed electric power and temperature. In short, the CNT films were biased in the air with DC (TTi $120 \mathrm{H}$ power supply, TTi, Huntingdon, UK) and the temperature of the ensemble was recorded with a pyrometer (Impac IPE 140, Advanced Energy Industries, CO, USA). At the beginning of the study, the accuracy of the temperature measurements acquired in a non-contact mode was cross-checked with a thermocouple and the outcomes were in accordance with each other. Stepwise change of bias voltage while measuring the temperature was conducted in the course of two consecutive runs from room temperature up to $300{ }^{\circ} \mathrm{C}$. The first run was regarded as a pretreatment step, during which heat-assisted evaporation of absorbed species takes place and causes a quasi-permanent change in resistance [28]. The values of electric power and the corresponding temperatures obtained from the second run in such a way enabled us to predict the temperature of the CNT films inside the glass chamber. An online temperature measurement was not possible inside of the enclosure wherein they were subsequently examined under various gaseous atmospheres.

\subsection{Electrical Measurements under Non-Ambient Conditions}

All samples evaluated in this work were prepared as specified before. They had an area of $10 \mathrm{~mm}$ $\times 40 \mathrm{~mm}$ and were pretreated as described above to remove as much adventitious contamination as possible coming from the synthesis stage and storage in the ambient. For these investigations, sample holders with CNT films were placed on the stage, crocodile clips leading to the power supply unit were connected to the $\mathrm{Al}$ tape electrical terminals, and then the glass chamber was properly sealed (Figure 2).

\subsubsection{Vacuum Experiments}

In the first experiment, a turbo vacuum pump was turned on while the CNT film was biased at $9 \mathrm{~V}$, which corresponded to $100^{\circ} \mathrm{C}$. We monitored the effect of pressure on the value of the current by bringing the vacuum to a certain level and maintaining it at this point until the electrical read-outs stabilized. We decreased the pressure in steps eventually reaching $5 \times 10^{-6}$ bar.

In the second experiment, we probed the influence of vacuum on current-voltage characteristics of the CNT films in the extended temperature range. In the beginning, the electrical behavior was tested in the air up $300^{\circ} \mathrm{C}$, so as to prevent oxidation. Then, we pumped the system down to $2 \times 10^{-6}$ bar and repeated the I-V measurements in the oxygen-deprived environment on the same CNT film. This time, however, we ramped up the bias voltage to the limits of the DC power supply. Notable incandescence from the sample was observed during this time (Figure 3). Lastly, we switched off the power supply unit and filled the chamber with air again. Then, we increased the bias voltage stepwise up to the failure point in air, which occurred at $461{ }^{\circ} \mathrm{C}$.

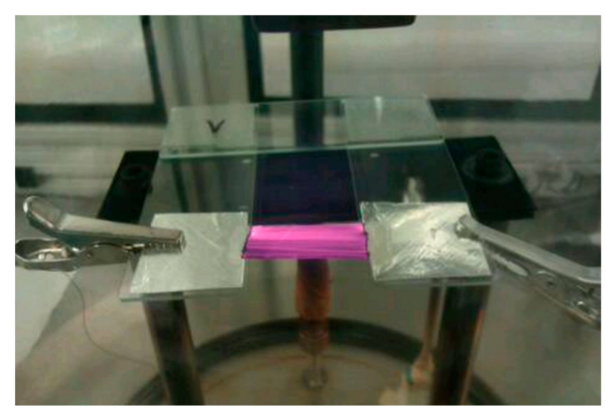

Figure 3. Incandescence from the CNT film at $67.5 \mathrm{~W}$ of delivered electric power.

\subsubsection{Artificial Atmosphere Experiments}

Once we evacuated the chamber and reached $2 \times 10^{-6}$ bar, we bled methane, acetylene, oxygen, ammonia, nitrogen, argon, or hydrogen into the system up to the point when the pressure gauge 
indicated $2 \times 10^{-2}$ bar. I-V data were collected on the samples again from room temperature up to $300{ }^{\circ} \mathrm{C}$ and compared with the behavior of the samples examined in air. We used the relation of employed electric power to the temperature of the material (described in Section 2.2) to determine the temperature of the CNT films inside the chamber.

\subsection{Characterization}

BET adsorption/desorption isotherms (Tristar 3000, Micromeritics Instruments Corporation, GA, USA) were recorded using $N_{2}$, wherein $P$ is the actual pressure and $P_{0}$ is the saturation pressure of $N_{2}$ at $77 \mathrm{~K}$. Prior to the measurement, the sample was outgassed at $140{ }^{\circ} \mathrm{C}$ overnight. Ten milligrams of the material were used for the measurement.

Scanning electron microscopy (SEM; JEOL6340 FEG SEM; Tokyo, Japan) was employed to observe the material microstructure and probe for the presence of carbonaceous adulterants before and after the electrothermal treatments.

Raman spectroscopy (Renishaw RM2000, $\lambda=633 \mathrm{~nm}$, HeNe $2 \mathrm{~mW}$; Wotton-under-Edge, UK) was used to acquire the intensity of the defect-induced band (D) as well as that of the band of vibrations of graphitic structures $(\mathrm{G}) . \mathrm{I}_{\mathrm{D}} / \mathrm{I}_{\mathrm{G}}$ ratio was employed for analysis, which is a common way to gauge the level of structural perfection of C-sp ${ }^{2}$ lattice in nanocarbon materials.

\section{Results}

\subsection{Experiments in Vacuum}

First, we probed the porous nature of our CNT films by using a nitrogen adsorption-desorption method at $77 \mathrm{~K}$ (Figure 4a). The material proved to have mostly meso- and macropores as expected from a CNT aerogel $[15,29]$. Its isotherm can be classified between II and IV types [30,31].

\section{(a)}

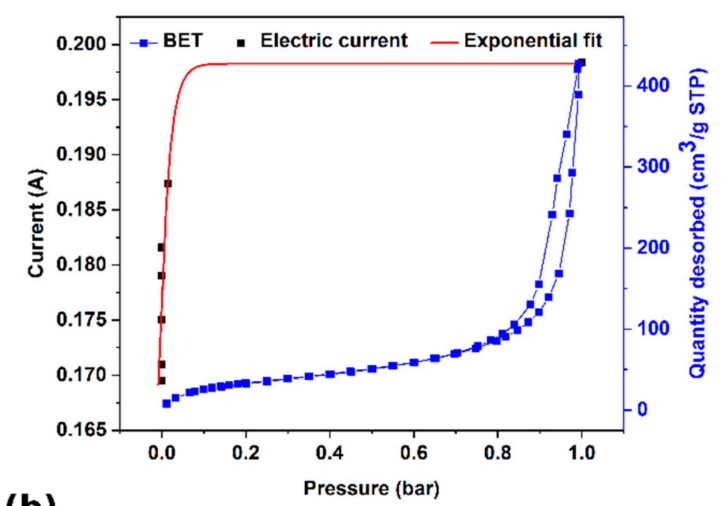

(b)

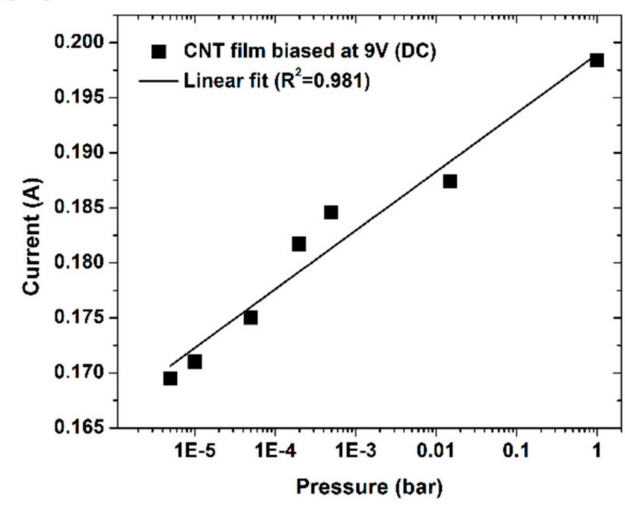

Figure 4. (a) Effect of pressure on the electrical conductivity of CNT films correlated with $\mathrm{N}_{2}$ desorption isotherm. (b) Electrical conductivity of CNT films as a function of pressure. 
In the enclosed plot, one can note that a monolayer of $\mathrm{N}_{2}$ is reached rapidly, then there is a plateau, at which multi-layer formation starts and, finally, hysteresis appears, which is indicative of capillary condensation. To get to know how various regimes of vacuum affect the conductivity of the CNT films, we measured their electrical properties at diminished pressure. Figure $4 \mathrm{~b}$ shows that the current is in logarithmic relation with pressure and decreases with improving the quality of the vacuum. It can be explained by the desorption of dopants present on the surface, which in the ambient conditions enhance the conductivity of CNT networks. The doping species that could come off the CNT films readily at such a low pressure are water [32,33] and oxygen [34] molecules. Their removal is particularly difficult as they are confined within the framework and structure of the CNT films and require a significant pressure difference to desorb them fully. A study by Chaban et al. [35] shows that water bound to the CNT network can, in fact, have elevated boiling point, so it is very difficult to fully get rid of it. We measured an $18 \%$ increase in resistance as the chamber with a CNT film was evacuated from ambient pressure down to $5 \times 10^{-6}$ bar at $100^{\circ} \mathrm{C}$. Since the increase in resistance with the level of vacuum did not seem to decelerate under the evaluated conditions, we may suspect that the CNT films are still doped to some extent. Finally, we brought the pressure down to $2 \times 10^{-6}$ bar and, once the electrical properties stabilized, we started increasing the bias voltage up to the limit of the DC power supply eventually reaching $67.5 \mathrm{~W}(77 \mathrm{~V} \times 0.877 \mathrm{~A})$. In these settings, the CNT film was glowing substantially due to the incandescence from the material [36] (Figure 3).

As shown in Figure $5 \mathrm{a}$, in the beginning, CNT films exhibit non-Ohmic behavior up to $150^{\circ} \mathrm{C}$. In this regime, heat-assisted removal of residual water as well as aliphatic and aromatic contaminants [37,38] from the synthesis stage takes place. These species readily deposit onto the nanocarbon due to relatively high porosity of the material and interfere with the observed electrical and/or surface properties [38].

\section{(a)}

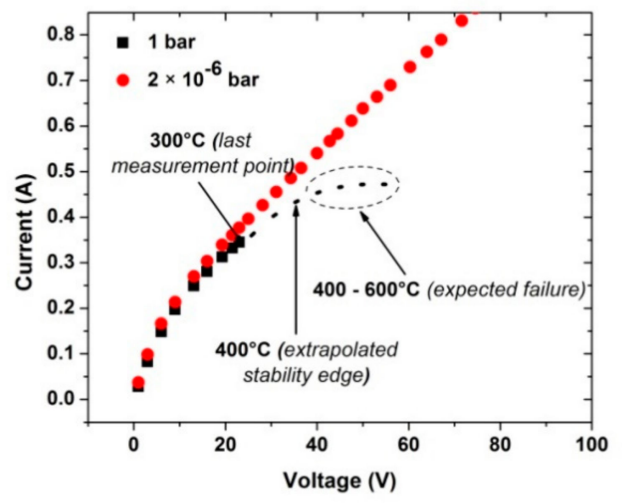

(b)

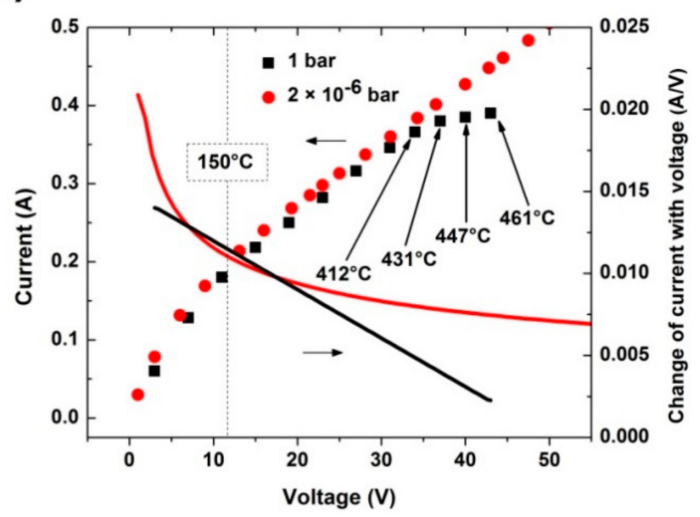

Figure 5. Effect of oxygen elimination on the electrical conductivity and thermal stability of CNT films (a) up to $300^{\circ} \mathrm{C}$ and (b) within the extended temperature range. 
As reported before, the evaporation of these species can give CNT films with Ohmic behavior in consecutive runs [15].

Furthermore, in the case of CNT films heated in air, we entered the edge of the thermal stability region beyond $300{ }^{\circ} \mathrm{C}$, which extends up to about $400{ }^{\circ} \mathrm{C}$ [39]. At this point, we can expect the electrical breakdown of the most conductive metallic CNTs because of high current densities $[40,41]$. Further increase in delivered electric power and hence the rise in temperature of the CNT films usually results in rapid oxidation at the temperatures between $400{ }^{\circ} \mathrm{C}$ and $600{ }^{\circ} \mathrm{C}$, which breaks the electric circuit. The actual failure temperature is dependent upon the composition of the CNT films. The number of constituting walls and the degree of structural perfection both have a strong impact on the electrothermal performance. It is commonly known that the least thermally stable CNT ensembles are composed of defected single-walled CNTs. In our case, the use of multi-walled CNTs and evacuation of the chamber suppressed this issue. Because of the lack of contact of the CNT films with air, they continued to exhibit linear I-V characteristics in the high-temperature regime. Closer investigation revealed that the increase of current with bias voltage under vacuum approaches a steady pace-the first derivative of the $I-V$ curve shown in Figure $5 b$ tends to a constant (in contrast to that of the sample heated in air).

Our next aim was to observe how different gaseous atmospheres affect the electrical properties of CNT films. The chamber was evacuated down to $2 \times 10^{-6}$ bar and then we bled selected gases up until the pressure of the artificial atmosphere had reached $2 \times 10^{-2}$ bar. We monitored the I-V characteristics of the CNT films between room temperature and $300^{\circ} \mathrm{C}$ in these conditions (Figure 6). An increase in resistance was observed in all of the cases except when the CNT film was exposed to hydrogen. Absorption of these species on the surface improved the mobility of the charge carriers.

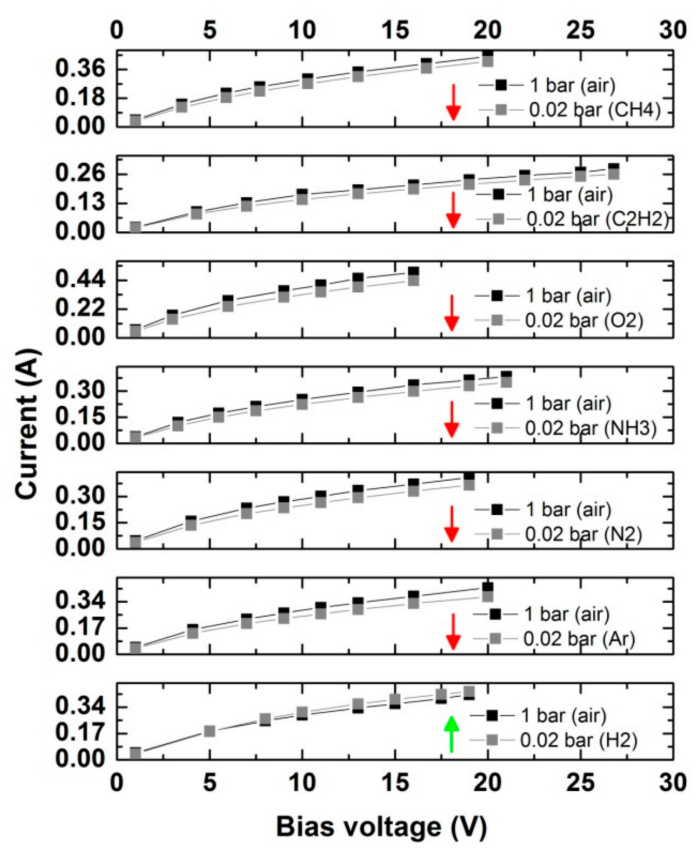

Figure 6. Gas effect on CNT films and their I-V characteristics (red arrow and green arrows indicate a decrease and increase in conductivity, respectively).

To analyze this effect in more detail, we normalized the resistance of the samples in various environments (by taking the I-V characteristics acquired in air as a reference) and compared the results (Figure 7a). We can see two types of behavior, i.e., a population of samples with increased resistance (exposed to methane, ethylene, oxygen, ammonia, nitrogen, and argon) and the sample for which the resistance decreased (exposed to hydrogen). The behavior of the former group of samples can be explained by the evaporation of water during the evacuation of the chamber. As it desorbs from the 
CNT films, its doping action fades, and thus we observe an upshift in resistance by about $15 \%$ over the whole temperature range (close to $18 \%$ observed in Section 3.1 for results obtained in vacuum justified by the same effect). It appears that, under such conditions, these gases do not affect the electrical properties of the material.

(a)

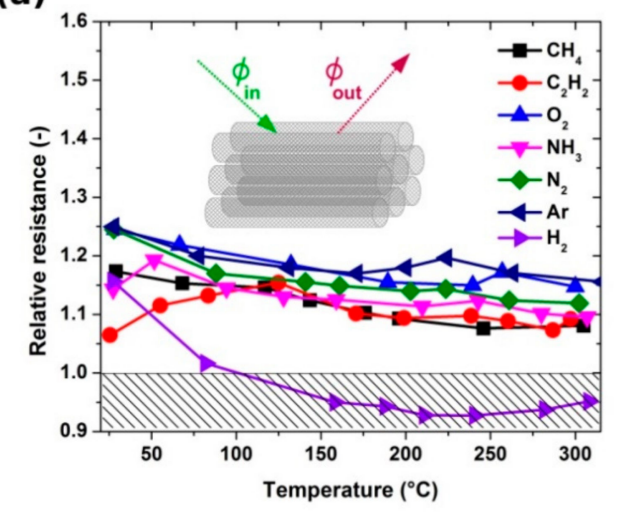

(b)

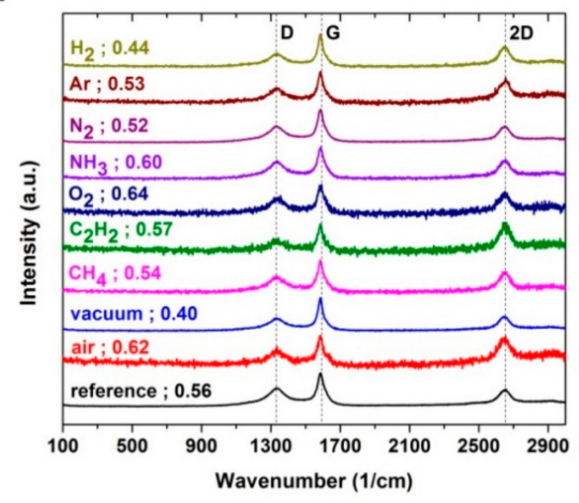

Figure 7. (a) Surrounding gas effect on the electrical conductivity of CNT films up to $300{ }^{\circ} \mathrm{C}$. (b) Raman spectra of CNT films: as-made and after the electrothermal treatments in various environments.

Hydrogen presence, on the other hand, overcame this phenomenon and gave a decrease in resistance. As depicted in the inset, there is always a net flux of gas, according to Fick's first law. Hydrogen diffuses into CNT networks very well [42,43] (diffusion coefficient is much higher than that of other employed gases), so we can expect that it will readily penetrate the structure of our CNT film, which is of the aerogel nature. It also has to be taken into consideration that nanocarbon strongly interacts with hydrogen, and hence they have been considered for a long time as a promising hydrogen storage material [44].

The hydrogen sensing properties of CNTs have been well-explored, but in most cases while covered with Pd particles at room temperature [45-49]. The reason for the addition of metal nanoparticles for such purposes is that hydrogen creates a hydride layer on the surface of Pd, which spills over the CNTs $[46,47]$. Our neat CNT films experienced a maximum sensitivity toward hydrogen at about $225{ }^{\circ} \mathrm{C}$, at which point the electrical resistance decreased by $7 \%$. CNTs themselves are capable of causing hydrogen dissociative adsorption and the process can be auto-accelerating [50]. There is an interplay between the role of temperature on net diffusion flux of gas as well as on the ability of hydrogen molecules to dissociate. The combined effect herein is a favorable decrease in resistance. One also has to keep in mind that, in fact, hydrogen affects the resistance to a larger degree because it counteracts the increase of resistance caused by the desorption of water from the CNT films under vacuum (the samples were first exposed to vacuum and then put in contact with hydrogen inside the glass chamber). 
Since CNT films kept at elevated temperatures under various gaseous environments can experience a change in chemical composition or microstructure [51], we characterized the samples before and after the treatment. Examination by Raman spectroscopy probed for the first type of modifications (Figure $7 \mathrm{~b}$ ). Exposure of the CNT films to inert gases $\left(\mathrm{N}_{2}\right.$, Ar) or hydrocarbons (acetylene, methane) did not cause appreciable alteration to the $\mathrm{I}_{\mathrm{D}} / \mathrm{I}_{\mathrm{G}}$ ratio and small differences may be accounted for by slight inhomogeneity of the material. That was expected from the chemistry of the material as neither CNTs nor present adulterants should react with them under these conditions. Moreover, the CNT films exposed to air or oxygen experienced an increase in the degree of disorder from 0.56 to 0.62 and 0.64 , respectively. The effect can be justified by partial oxidation of non-volatile and defective carbonaceous deposits present on the surface of the material as reported previously [37]. The only other gas that caused a noticeable increase in $\mathrm{I}_{\mathrm{D}} / \mathrm{I}_{\mathrm{G}}$ ratio up to 0.60 was ammonia, which can readily react under these conditions with amorphous carbon or these contamination species present in our material [52]. An opposite effect was observed when the hydrogen atmosphere was employed. We noted a decrease in $\mathrm{I}_{\mathrm{D}} / \mathrm{I}_{\mathrm{G}}$ ratio from 0.56 to 0.44 explained by the hydrogen reduction of certain defects on the surface. Finally, the most significant improvement was noted due to the action of vacuum when the CNT film was brought up to the point of incandescence. High-temperature annealing under inert environments has a favorable influence on the degree of graphitization of the CNT assemblies [53,54], so we can expect a similar effect when resistive heating is employed for this purpose herein. Lastly, the analysis of the microstructure by electron microscopy did not visualize detectable changes done by the electrothermal treatment under various conditions (Figures S1 and S2). It can be concluded that any changes to the material detected by Raman spectroscopy take place at the level of individual CNTs while the ensemble, in general, remains intact. Deposits of amorphous carbon introduced during the synthesis persist in the CNT film despite the high-temperature treatment. This is to be expected because usually healing of CNT defects and removal of carbonaceous species is conducted at more than $2000^{\circ} \mathrm{C}$. At this point, it is also important to stress that control experiments conducted by us on annealed multi-walled CNT films revealed that the presence of residual catalysts had a negligible effect on the way the electrical conductivity of the films responded to various gaseous atmospheres. The differences between treated and untreated materials were within statistical error. Therefore, the observed sensorial action comes solely from the nanocarbon.

\section{Conclusions}

The surrounding gas atmosphere can make a significant impact on the electrical conductivity of multi-walled CNT ensembles. As we subjected CNT films to various grades of vacuum, we observed that diminished pressure results in desorption of water (and other contaminants), which is correlated with an increase in their electrical resistance. This transforms the material into a conductor of an Ohmic type. What is more, the electrical properties of multi-walled CNT films are affected the most by exposing them to hydrogen, adsorption of which improves the mobility of charge carriers. We believe that the observed sensitivity of the electrical properties of the multi-walled CNT films to hydrogen or vacuum at elevated temperatures could be of practical importance. The findings can give rise to the development of a special grade of sensors for industrial applications since many processes in this field operate at elevated temperatures. Lastly, significant light emission in vacuum at high bias indicates that the CNT films can sustain notable current densities. It once again demonstrates that the elimination of the issue of contact resistance between individual CNTs in an ensemble should bring the conductivity of the network much closer to the theoretical limits obtained for individual CNTs.

Supplementary Materials: The following are available online at http://www.mdpi.com/1996-1944/13/3/510/s1, Figure S1: SEM micrographs CNT films as made and after the electrothermal treatment in air, vacuum, methane, and ethylene; Figure S2: SEM micrographs CNT films after the electrothermal treatment in oxygen, ammonia, nitrogen, argon, and hydrogen. 
Author Contributions: Conceptualization, D.J.; data curation, D.J.; formal analysis, D.J. and K.K.K.; funding acquisition, D.J. and K.K.K.; investigation, D.J. and K.K.K.; methodology, D.J. and K.K.K.; project administration, D.J. and K.K.K.; resources, D.J. and K.K.K.; supervision, D.J. and K.K.K.; validation, D.J. and K.K.K.; visualization, D.J.; writing - original draft, D.J. and K.K.K.; writing - review and editing, D.J. and K.K.K. All authors have read and agreed to the published version of the manuscript.

Funding: We acknowledge the National Centre for Research and Development, Poland (under the Leader program, grant agreement LIDER/0001/L-8/16/NCBR/2017) and the European Research Council (under the Seventh Framework Program FP7/2007-2013, ERC grant agreement 259061).

Acknowledgments: We thank Matthew Cole (University of Cambridge) for providing technical expertise.

Conflicts of Interest: The authors declare no conflicts of interest. The funders had no role in the design of the study; in the collection, analyses, or interpretation of data; in the writing of the manuscript, or in the decision to publish the results.

\section{References}

1. Iijima, S. Helical microtubules of graphitic carbon. Nature 1991, 354, 56-58. [CrossRef]

2. Brady, G.J.; Way, A.J.; Safron, N.S.; Evensen, H.T.; Gopalan, P.; Arnold, M.S. Quasi-ballistic carbon nanotube array transistors with current density exceeding Si and GaAs. Sci. Adv. 2016, 2, e1601240. [CrossRef] [PubMed]

3. Cai, L.; Wang, C. Carbon Nanotube Flexible and Stretchable Electronics. Nanoscale Res. Lett. 2015, 10, 320. [CrossRef] [PubMed]

4. Kumanek, B.; Janas, D. Thermal conductivity of carbon nanotube networks: A review. J. Mater. Sci. 2019, 54, 7397-7427. [CrossRef]

5. Arash, B.; Wang, Q.; Varadan, V.K. Mechanical properties of carbon nanotube/polymer composites. Sci. Rep. 2014, 4, 6479. [CrossRef] [PubMed]

6. Yang, W.D.; Wang, X. Nonlinear pull-in instability of carbon nanotubes reinforced nano-actuator with thermally corrected Casimir force and surface effect. Int. J. Mech. Sci. 2016, 107, 34-42. [CrossRef]

7. Yu, W.-J.; Liu, C.; Hou, P.-X.; Zhang, L.; Shan, X.-Y.; Li, F.; Cheng, H.-M. Lithiation of Silicon Nanoparticles Confined in Carbon Nanotubes. ACS Nano 2015, 9, 5063-5071. [CrossRef]

8. Arash, B.; Wang, Q. Detection of gas atoms with carbon nanotubes. Sci. Rep-Uk 2013, 3, 1782. [CrossRef]

9. Yeh, Y.-T.; Lin, Z.; Zheng, S.-Y.; Terrones, M. A carbon nanotube integrated microfluidic device for blood plasma extraction. Sci. Rep. 2018, 8, 13623. [CrossRef]

10. Liang, S.; Ma, Z.; Wei, N.; Liu, H.; Wang, S.; Peng, L.-M. Solid state carbon nanotube device for controllable trion electroluminescence emission. Nanoscale 2016, 8, 6761-6769. [CrossRef]

11. Wang, X.; Zhu, D.; Yang, X.; Yuan, L.; Li, H.; Wang, J.; Chen, M.; Deng, G.; Liang, W.; Li, Q.; et al. Stressed carbon nanotube devices for high tunability, high quality factor, single mode GHz resonators. Nano Res. 2018, 11, 5812-5822. [CrossRef]

12. Ericson, L.M.; Fan, H.; Peng, H.Q.; Davis, V.A.; Zhou, W.; Sulpizio, J.; Wang, Y.H.; Booker, R.; Vavro, J.; Guthy, C.; et al. Macroscopic, neat, single-walled carbon nanotube fibers. Science 2004, 305, 1447-1450. [CrossRef] [PubMed]

13. Li, Y.L.; Kinloch, I.A.; Windle, A.H. Direct spinning of carbon nanotube fibers from chemical vapor deposition synthesis. Science 2004, 304, 276-278. [CrossRef] [PubMed]

14. Zhang, M.; Atkinson, K.R.; Baughman, R.H. Multifunctional carbon nanotube yarns by downsizing an ancient technology. Science 2004, 306, 1358-1361. [CrossRef]

15. Janas, D.; Koziol, K.K. Rapid electrothermal response of high-temperature carbon nanotube film heaters. Carbon 2013, 59, 457-463. [CrossRef]

16. Aliev, A.E.; Gartstein, Y.N.; Baughman, R.H. Mirage effect from thermally modulated transparent carbon nanotube sheets. Nanotechnology 2011, 22, 435704. [CrossRef]

17. Butt, H.; Montelongo, Y.; Butler, T.; Rajesekharan, R.; Dai, Q.; Shiva-Reddy, S.G.; Wilkinson, T.D.; Amaratunga, G.A.J. Carbon Nanotube Based High Resolution Holograms. Adv. Opt. Mater. 2012, 24, 331-336. [CrossRef]

18. Zaporotskova, I.V.; Boroznina, N.P.; Parkhomenko, Y.N.; Kozhitov, L.V. Carbon nanotubes: Sensor properties. A review. Mod. Electron. Mater. 2016, 2, 95-105. [CrossRef] 
19. Worsley, M.A.; Stadermann, M.; Wang, Y.M.M.; Satcher, J.H.; Baumann, T.F. High surface area carbon aerogels as porous substrates for direct growth of carbon nanotubes. Chem. Commun. 2010, 46, 9253-9255. [CrossRef]

20. Xiao, M.; Liang, S.; Han, J.; Zhong, D.; Liu, J.; Zhang, Z.; Peng, L. Batch Fabrication of Ultrasensitive Carbon Nanotube Hydrogen Sensors with Sub-ppm Detection Limit. ACS Sens. 2018, 3, 749-756. [CrossRef]

21. Rajavel, K.; Lalitha, M.; Radhakrishnan, J.K.; Senthilkumar, L.; Rajendra Kumar, R.T. Multiwalled Carbon Nanotube Oxygen Sensor: Enhanced Oxygen Sensitivity at Room Temperature and Mechanism of Sensing. ACS Appl. Mater. Interfaces 2015, 7, 23857-23865. [CrossRef] [PubMed]

22. Chimowa, G.; Tshabalala, Z.P.; Akande, A.A.; Bepete, G.; Mwakikunga, B.; Ray, S.S.; Benecha, E.M. Improving methane gas sensing properties of multi-walled carbon nanotubes by vanadium oxide filling. Sens. Actuators B Chem. 2017, 247, 11-18. [CrossRef]

23. Agarwal, P.B.; Alam, B.; Sharma, D.S.; Sharma, S.; Mandal, S.; Agarwal, A. Flexible $\mathrm{NO}_{2}$ gas sensor based on single-walled carbon nanotubes on polytetrafluoroethylene substrates. Flex. Print. Electron. 2018, 3, 035001. [CrossRef]

24. Zhang, X.; Cui, H.; Gui, Y.; Tang, J. Mechanism and Application of Carbon Nanotube Sensors in $\mathrm{SF}_{6}$ Decomposed Production Detection: A Review. Nanoscale Res. Lett. 2017, 12, 177. [CrossRef] [PubMed]

25. Septiani, N.L.W.; Yuliarto, B. The development of gas sensor based on carbon nanotubes. J. Electrochem. Soc. 2016, 163, B97-B106. [CrossRef]

26. Young, S.; Lin, Z. Ammonia gas sensors with Au-decorated carbon nanotubes. Microsyst. Technol. 2018, 24, 4207-4210. [CrossRef]

27. Janas, D.; Koziol, K.K. Carbon nanotube fibers and films: Synthesis, applications and perspectives of the direct-spinning method. Nanoscale 2016, 8, 19475-19490. [CrossRef]

28. Lekawa-Raus, A.; Kurzepa, L.; Kozlowski, G.; Hopkins, S.C.; Wozniak, M.; Lukawski, D.; Glowacki, B.A.; Koziol, K.K. Influence of atmospheric water vapour on electrical performance of carbon nanotube fibres. Carbon 2015, 87, 18-28. [CrossRef]

29. Jung, S.M.; Jung, H.Y.; Dresselhaus, M.S.; Jung, Y.J.; Kong, J. A facile route for 3D aerogels from nanostructured 1D and 2D materials. Sci. Rep. 2012, 2, 849. [CrossRef]

30. Sing, K.S.W.; Everett, D.H.; Haul, R.A.W.; Moscou, L.; Pierotti, R.A.; Rouquerol, J.; Siemieniewska, T. Reporting Physisorption Data for Gas Solid Systems with Special Reference to the Determination of Surface-Area and Porosity (Recommendations 1984). Pure Appl. Chem. 1985, 57, 603-619. [CrossRef]

31. Jiang, Q.; Zhao, Y. Effects of activation conditions on BET specific surface area of activated carbon nanotubes. Microporous Mesoporous Mater. 2004, 76, 215-219. [CrossRef]

32. Moonoosawmy, K.R.; Kruse, P. Cause and Consequence of Carbon Nanotube Doping in Water and Aqueous Media. J. Am. Chem. Soc. 2010, 132, 1572-1577. [CrossRef] [PubMed]

33. Zahab, A.; Spina, L.; Poncharal, P.; Marliere, C. Water-vapor effect on the electrical conductivity of a single-walled carbon nanotube mat. Phys. Rev. B 2000, 62, 10000-10003. [CrossRef]

34. Roch, A.; Greifzu, M.; Talens, E.R.; Stepien, L.; Roch, T.; Hege, J.; Van Nong, N.; Schmiel, T.; Dani, I.; Leyens, C.; et al. Ambient effects on the electrical conductivity of carbon nanotubes. Carbon 2015, 95, 347-353. [CrossRef]

35. Chaban, V.V.; Prezhdo, V.V.; Prezhdo, O.V. Confinement by Carbon Nanotubes Drastically Alters the Boiling and Critical Behavior of Water Droplets. ACS Nano 2012, 6, 2766-2773. [CrossRef]

36. Wei, J.Q.; Zhu, H.W.; Wu, D.H.; Wei, B.Q. Carbon nanotube filaments in household light bulbs. Appl. Phys. Lett. 2004, 84, 4869-4871. [CrossRef]

37. Janas, D.; Sundaram, R.; Koziol, K.K.K. Surface modification of directly spun carbon nanotube films. Mater Lett. 2012, 79, 32-34. [CrossRef]

38. Stando, G.; Łukawski, D.; Lisiecki, F.; Janas, D. Intrinsic hydrophilic character of carbon nanotube networks. Appl. Surf. Sci. 2019, 463, 227-233. [CrossRef]

39. Janas, D.; Koziol, K.K. Improved Performance of Ultra-Fast Carbon Nanotube Film Heaters. J. Autom. Control Eng. Vol 2014, 2, 150-153. [CrossRef]

40. Collins, P.G.; Arnold, M.S.; Avouris, P. Engineering Carbon Nanotubes and Nanotube Circuits Using Electrical Breakdown. Science 2001, 292, 706. [CrossRef]

41. Collins, P.G.; Hersam, M.; Arnold, M.; Martel, R.; Avouris, P. Current Saturation and Electrical Breakdown in Multiwalled Carbon Nanotubes. Phys. Rev. Lett. 2001, 86, 3128-3131. [CrossRef] [PubMed] 
42. Dillon, A.C.; Jones, K.M.; Bekkedahl, T.A.; Kiang, C.H.; Bethune, D.S.; Heben, M.J. Storage of hydrogen in single-walled carbon nanotubes. Nature 1997, 386, 377-379. [CrossRef]

43. Liu, C.; Fan, Y.Y.; Liu, M.; Cong, H.T.; Cheng, H.M.; Dresselhaus, M.S. Hydrogen storage in single-walled carbon nanotubes at room temperature. Science 1999, 286, 1127-1129. [CrossRef] [PubMed]

44. Cheng, H.-M.; Yang, Q.-H.; Liu, C. Hydrogen storage in carbon nanotubes. Carbon 2001, 39, 1447-1454. [CrossRef]

45. Sun, Y.G.; Wang, H.H. High-performance, flexible hydrogen sensors that use carbon nanotubes decorated with palladium nanoparticles. Adv. Mater. 2007, 19, 2818-2823. [CrossRef]

46. Khalap, V.R.; Sheps, T.; Kane, A.A.; Collins, P.G. Hydrogen Sensing and Sensitivity of Palladium-Decorated Single-Walled Carbon Nanotubes with Defects. Nano Lett. 2010, 10, 896-901. [CrossRef]

47. Ganzhorn, M.; Vijayaraghavan, A.; Dehm, S.; Hennrich, F.; Green, A.A.; Fichtner, M.; Voigt, A.; Rapp, M.; von Lohneysen, H.; Hersam, M.C.; et al. Hydrogen Sensing with Diameter- and Chirality-Sorted Carbon Nanotubes. ACS Nano 2011, 5, 1670-1676. [CrossRef]

48. Ventura, D.N.; Li, S.; Baker, C.A.; Breshike, C.J.; Spann, A.L.; Strouse, G.F.; Kroto, H.W.; Acquah, S.F.A. A flexible cross-linked multi-walled carbon nanotube paper for sensing hydrogen. Carbon 2012, 50, 2672-2674. [CrossRef]

49. Rumiche, F.; Wang, H.H.; Indacochea, J.E. Development of a fast-response/high-sensitivity double wall carbon nanotube nanostructured hydrogen sensor. Sens. Actuators B Chem. 2012, 163, 97-106. [CrossRef]

50. Zhang, Z.Y.; Cho, K. Ab initio study of hydrogen interaction with pure and nitrogen-doped carbon nanotubes. Phys. Rev. B 2007, 75, 075420. [CrossRef]

51. Talyzin, A.V.; Luzan, S.; Anoshkin, I.V.; Nasibulin, A.G.; Jiang, H.; Kauppinen, E.I.; Mikoushkin, V.M.; Shnitov, V.V.; Marchenko, D.E.; Noreus, D. Hydrogenation, Purification, and Unzipping of Carbon Nanotubes by Reaction with Molecular Hydrogen: Road to Graphane Nanoribbons. ACS Nano 2011, 5, 5132-5140. [CrossRef] [PubMed]

52. Yin, L.W.; Bando, Y.; Li, M.S.; Liu, Y.X.; Qi, Y.X. Unique single-crystalline beta carbon nitride nanorods. Adv. Mater. 2003, 15, 1840-1844. [CrossRef]

53. Huang, W.; Wang, Y.; Luo, G.H.; Wei, F. 99.9\% purity multi-walled carbon nanotubes by vacuum high-temperature annealing. Carbon 2003, 41, 2585-2590. [CrossRef]

54. Jung, S.I.; Jo, S.H.; Moon, H.S.; Kim, J.M.; Zang, D.S.; Lee, C.J. Improved crystallinity of double-walled carbon nanotubes after a high-temperature thermal annealing and their enhanced field emission properties. J. Phys. Chem. C 2007, 111, 4175-4179. [CrossRef] 